\title{
Conforto térmico em espaços abertos no clima quente e úmido: estudo de caso em um parque urbano no Bioma Mata Atlântica
}

\author{
Outdoor thermal comfort in a hot and humid climate: \\ case study in an urban park in the Atlantic Forest Biome
}

\section{Linccon de Carvalho Lima \\ Solange Maria Leder \\ Luiz Bueno da Silva \\ Erivaldo Lopes de Souza}

\section{Resumo}

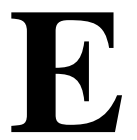

studos de conforto térmico em espaços climatizados apresentam limitações ao desconsiderar a adaptação do indivíduo às condições ambientais. Com objetivo de superar as limitações dos modelos atuais de conforto térmico, pesquisas têm sido realizadas para identificar os limites de conforto em ambientes sem climatização e em condições naturais, dentre elas, destacam-se os estudos de conforto em espaços abertos. Nesse contexto, este estudo tem como objetivo geral avaliar a sensação térmica dos visitantes de um parque urbano em João Pessoa-PB, uma cidade de clima quente e úmido no nordeste do Brasil. O Parque Urbano utilizado como área de estudo é uma das principais áreas verdes da cidade de João Pessoa. A metodologia aplicada utilizou de monitoramento microclimático das variáveis: temperatura do ar, temperatura do globo, umidade relativa do ar, velocidade do ar e radiação solar. Também foram aplicados 900 questionários estruturados para avaliar a sensação térmica dos usuários. Os resultados mostraram que $70 \%$ dos entrevistados estavam confortáveis quando a temperatura do ar estava entre 26 e $31^{\circ} \mathrm{C}$. Através de modelagem matemática observou-se que existe efeito significativo das variáveis ambientais sobre a sensação térmica real. Comparando a sensação térmica com os índices calculados PMV, SET e PET, o intervalo encontrado para o índice PET de 24 a $34^{\circ} \mathrm{C}$ foi o que melhor refletiu a sensação térmica real dos entrevistados.

Palavras-chaves: Parque Urbano. Sensação térmica. Espaços abertos.

${ }^{1}$ Linccon de Carvalho Lima ${ }^{1}$ Universidade Federal da Paraíba J oão Pessoa - PB - Brasil

${ }^{2}$ Solange Maria Leder ${ }^{2}$ Universidade Federal da Paraíba J oão Pessoa - PB - Brasil

${ }^{3}$ Luiz Bueno da Silva ${ }^{3}$ Universidade Federal da Paraíba J oão Pessoa - PB - Brasil

${ }^{4}$ Erivaldo Lopes de Souza ${ }^{4}$ Universidade Federal da Paraíba J oão Pessoa - PB - Brasil

Recebido em 09/04/18 Aceito em 02/07/18

\section{Abstract}

One of the limitations of thermal comfort studies in air-conditioned spaces is that they often ignore the fact that people have the capacity to adapt to their surroundings. In order to overcome the limitations of current thermal comfort models, several research studies have been carried out to identify comfort standards in free-running buildings, including studies of thermal comfort in open spaces. The aim of this study is to evaluate the thermal sensation of visitors to an urban park in João Pessoa-PB, a city with hot and humid climate in the northeast of Brazil. The urban park used as study area is one of the main green areas of the city. The applied methodology included the use of microclimatic monitoring of the variables: air temperature, globe temperature, air humidity, air velocity and solar radiation. We carried out 900 interviews to evaluate users' thermal sensation. The results showed that $70 \%$ of respondents were comfortable when the air temperature was between 26 and $31^{\circ} \mathrm{C}$. Though mathematical modelling it was possible to observe that environmental variables significantly affect the actual thermal sensation. A comparison between thermal sensation and the calculated indices PMV, SET and PET showed that the PET index rage between 24 and 34 ${ }^{\circ} \mathrm{C}$ was the one that best reflected the actual thermal sensation of the interviewees. Keywords: Urban Park. Thermal sensation. Open spaces. 


\section{Introdução}

O conforto térmico influencia nas atividades diárias, na produtividade e no bem estar das pessoas. Assim, estudos sobre conforto térmico são indispensáveis para entender os efeitos do clima e as respostas do ser humano as variações climáticas. Entende-se por conforto térmico, o momento em que a as trocas de calor entre homem e o ambiente não causam incômodo (MONTEIRO, 1990). O conforto térmico não é estático, sendo o homem capaz de se adaptar as condições térmicas ao qual está inserido através de diferentes mecanismos de termorregulação (HUMPHREYS, 1978). Assim, além dos aspectos físicos e ambientais, o conforto térmico pode ser influenciado por fatores psicológicos e fisiológicos, de modo que, indivíduos inseridos em uma mesma condição climática podem relatar sensação térmica distinta (NIKOLOPOULOU; STEEMERS, 2003; NÓBREGA; LEMOS, 2011). Pesquisas com foco na determinação de padrões de conforto térmico através da análise das condições climáticas, da forma urbana e da opinião dos usuários contribuem significativamente para o avanço do conhecimento sobre as condições de conforto térmico em espaços abertos (BARBOSA, 2005; HIRASHIMA, 2010). Neste contexto, este trabalho tem como objetivo geral descrever as condições microclimáticas de um Parque urbano da cidade de João Pessoa-PB, e avaliar as relações entre as variáveis microclimáticas (temperatura do ar, umidade relativa do ar, velocidade do ar, radiação solar e temperatura radiante média) e as variáveis qualitativas (sensação térmica, condição térmica e preferência térmica). Por fim se propõem ainda a sugerir um intervalo de conforto térmico com base nas respostas subjetivas, nas variáveis ambientais e nos índices de conforto térmico PMV, PET e SET.

\section{Referencial teórico}

Com os avanços nas pesquisas sobre conforto térmico muitos índices e modelos preditivos têm sido propostos. O Voto Médio Predito (PMV Predicted Mean Vote) desenvolvido por Fanger (1970) e incluído na norma ISO 7730 (INTERNATIONAL..., 2005), é o índice de conforto mais utilizado nos estudos de conforto térmico. O índice é bastante eficaz em ambientes controlados, porém em ambientes abertos é mais indicado a utilização de índices como o PET (Equivalent Physiological Temperature) criado por Hoppe (1999). O PET é baseado no Modelo de Balanço Energético de Munique para Indivíduos (MEMI). É recomendado pela norma alemã VDI 3787/2008 para caracterização do estresse térmico em ambientes urbanos (HIRASHIMA, 2014). Este índice vem sendo frequentemente aplicado em pesquisas brasileiras devido à facilidade de uso do software RayMan (MATZARAKIS; RUTZ; MAYER, 2006; LABAKI et al., 2012). Outro índice bastante utilizado é o SET (Standard Effective Temperature) proposto por Gagge et al. (1986), obtido através de modelo analítico de conforto térmico. Entre 2001 e 2004 o projeto RUROS (Rediscovering the Urban Realm and Open Spaces) (2016) coletou dados microclimáticos e de satisfação térmica em cinco países da Europa: Grécia (Atenas e Tessalônica), Itália (Milão), Suíça (Fribourg), Inglaterra (Cambridge e Sheffield) e Alemanha (Kassel) propondo um modelo preditivo capaz de ser utilizado para avaliação do conforto térmico em diferentes condições climáticas da Europa, o ASV - Actual Sensation Vote (NIKOLOPOULOU; LYKOUDIS, 2006). O ASV utiliza a sensação térmica como variável dependente e a temperatura do ar, a umidade relativa do ar, a radiação solar e a velocidade do ar como variáveis independentes (ROSSI; KRUGER; BRODE, 2012). Tsitoura, Tsoutsos e Daras (2014) utilizaram do método ASV e dos índices PMV, PET, SET, WBGT (Wet Bulb Globe Temperature) para avaliar o uso do espaço público através do conforto térmico. O PMV foi capaz de prever aumento ou queda dos votos de conforto, sendo, a radiação solar fator predominante na sensação térmica. Ruiz e Correa (2015) propõem um modelo adaptativo para prever as condições de conforto térmico em populações adaptadas ao clima árido (Mendoza-Argentina). Analisando a sensação real coletada através de questionários e três variáveis microclimáticas foi sugerido um índice de conforto térmico para as cidades de Zonas Áridas (IZA). Comparado a outros índices de conforto como o PET e PMV, o IZA apresentou melhor eficiência na capacidade preditiva de conforto térmico em climas áridos. Nos estudos de Mahmoud (2011) o conforto térmico foi investigado em nove pontos de um parque urbano em clima quente e seco (CairoEgito). Foram coletadas variáveis microclimáticas e aplicados questionários de percepção térmica com os usuários. Os resultados demonstraram condições térmicas confortáveis entre PET 22 e $30{ }^{\circ} \mathrm{C}$ no período quente e $21^{\circ} \mathrm{C}$ a $29^{\circ} \mathrm{C}$ no período frio. Contudo, os locais apresentaram diferentes condições de radiação solar (fator do céu) e ventilação, resultando em avaliações distintas de conforto. Ng e Cheng (2012) investigaram as condições de conforto térmico de pedestres em espaços urbanos abertos na cidade de Hong KongChina. As variáveis ambientais que mais influenciaram na sensação do conforto foram: temperatura do ar, velocidade do ar e intensidade da radiação solar. O PET mais aceitável no verão esteve de 27 a $29^{\circ} \mathrm{C}$, sendo a faixa de $28{ }^{\circ} \mathrm{C}$ aceita 
como PET neutro. No Brasil existe grande contribuição dos estudos com conforto térmico em espaços abertos realizados por Monteiro e Alucci (2007); os autores realizaram uma ampla revisão conceitual acerca do tema e a calibração de vinte modelos preditivos para avaliar o conforto térmico em espaços externos na cidade de São Paulo-SP. A calibração de Monteiro foi utilizada como referência por diferentes autores. Dacanal, Labaki e Silva (2010) utilizaram questionários estruturados e os índices PMV e PET para avaliar a influência de fragmentos florestais urbanos no conforto térmico na cidade de Campinas-SP; cerca de 72\% dos entrevistados estiveram confortáveis entre intervalo PET de 18 a $26{ }^{\circ} \mathrm{C}$ e $39 \%$ estavam na faixa de conforto do PMV entre -0,5 e +0,5. Utilizando a calibração proposta por Monteiro e Alucci (2007) a PET esteve mais correlacionada com os votos de conforto real, enquanto o PMV apresentou menor correlação. Contribuições mais recentes foram realizadas por Labaki et al. (2012) que realizaram um estudo de conforto térmico em espaços públicos de passagem em três cidades do Estado de São Paulo-SP. Através de monitoramento climático e a aplicação de entrevistas estruturadas foram encontradas diferenças entre a sensação real (ASV) e o índice PET. Os limites de conforto térmico variaram entre as cidades: de $20{ }^{\circ} \mathrm{C}$ a $29{ }^{\circ} \mathrm{C}$ em Campinas, de $21{ }^{\circ} \mathrm{C}$ a $30{ }^{\circ} \mathrm{C}$ em Bauru, e em Presidente Prudente de $14{ }^{\circ} \mathrm{C}$ a $24^{\circ} \mathrm{C}$. A sensação de neutralidade térmica para 59,5\% da amostra ocorreu no intervalo de $18{ }^{\circ} \mathrm{C}$ a $26^{\circ} \mathrm{C}$. Rossi, Kruger e Brode (2012) analisaram a sensação de conforto térmico em espaços abertos na cidade de CuritibaPR, através dos índices de PMV, PET e UTCI (Universal Thermal Climate Index) desenvolvendo um modelo de predição da sensação térmica para Curitiba. Os três índices testados subestimaram a quantidade de pessoas em desconforto para o calor, sugerindo que os índices analisados precisam ser calibrados para as condições climáticas estudadas. Hirashima (2014) buscou verificar o efeito do índice PET sobre a de sensação térmica para cidade de Belo Horizonte-BH. Através de modelagem matemática o índice PET foi capaz de explicar 42\% da ocorrência da avaliação subjetiva predizendo $68 \%$ das respostas corretas.

\section{Método}

Esta pesquisa compreende o levantamento de variáveis ambientais e a aplicação de questionários de percepção de conforto térmico com visitantes em um parque zoobotânico inserido no meio urbano. O detalhamento dos procedimentos adotados será descrito nos seguintes itens:

(a) caracterização da área de estudo; (b) levantamento das variáveis ambientais;

(c) entrevista com os usuários - coleta das variáveis qualitativas e dependentes; e

(d) tratamento e análise dos dados.

\section{Caracterização da área de estudo}

O local das medições microclimáticas e da aplicação dos questionários com os visitantes é um parque zoobotânico com área de 26,8 hectares inserido no meio urbano da cidade de João Pessoa$\mathrm{PB}$, entre as coordenadas $7^{\circ} 06^{\prime} 51.32$ ''S e 3452'38.70’’O (Figura 1). Implantado no Bioma Mata Atlântica, o parque abriga diversas espécies da fauna e flora endêmica e exótica. É frequentado por moradores e turistas de diferentes regiões. Utilizado principalmente para contemplação da natureza, prática de atividades, passeio, recreação, sociabilidade e descanso. Foi criado em 1921 e inaugurado em 1922. Em 1980 foi reconhecido pelo IPHAEP (Instituto do Patrimônio Histórico e Artístico do Estado da Paraíba) como bem de interesse histórico estadual e em 1999 foi registrado junto ao Instituto Brasileiro de Meio Ambiente e Recursos Naturais Renováveis (IBAMA) como Parque Zoobotânico Arruda Câmara. O macroclima local é quente e úmido, as médias anuais de temperatura do ar estão em torno dos $25^{\circ} \mathrm{C}$, a média mínima está em torno dos $23^{\circ} \mathrm{C}$ e a média máxima em $28{ }^{\circ} \mathrm{C}$. Com duas estações, inverno e verão, o inverno se caracteriza pela redução da temperatura do ar e o aumento da pluviosidade. As chuvas chegam até $1.700 \mathrm{~mm}$ por ano.

\section{Levantamento das variáveis ambientais}

As variáveis microclimáticas: temperatura do ar; umidade relativa do ar; velocidade do ar e radiação solar foram monitoradas por uma estação meteorológica portátil Davis Vantage Pro2. A estação possui um conjunto de sensores integrados de temperatura do ar (resolução $0,1^{\circ} \mathrm{C}$; precisão 0,5 ${ }^{\circ} \mathrm{C}$ ), umidade do ar (resolução $1 \%$; precisão $3 \%$ ), pluviômetro (resolução 0 a 9999 mm; precisão 4\%) e anemômetro (resolução 1 a 67 m/s; precisão 5\%). Já temperatura do globo foi monitorada por um medidor de stress térmico TGD-300-Instrutherm, composto por um sensor de bulbo seco, um sensor de bulbo úmido e um globo térmico (resolução 0,1 ${ }^{\circ} \mathrm{C}$; precisão $0,5^{\circ} \mathrm{C}$ ). Os aparelhos foram instalados dispondo os sensores a 1,5 metros do solo, na sombra. Um intervalo de 20 minutos (especificações recomendadas pelo fabricante) para estabilização dos equipamentos foi respeitado no início das medições. As variáveis foram registradas automaticamente a cada 1 minuto, tendo início às 9 
horas e término às 16 horas, durante 22 dias, sendo 12 dias no período seco e 10 no período úmido (Quadro 1). A confiabilidade dos equipamentos foi previamente checada por técnicos do Instituto Nacional de Pesquisas Espaciais (INPE) sediado no Rio Grande do Norte (RN) e do Laboratório de Metrologia (Lab-Metrol) da UFRN. O local das medições é uma área aberta, protegida do sol por árvores de grande porte. Há intenso fluxo de pessoas e o passeio possui revestimento impermeável (Figuras 2 e 3). As entrevistas ocorreram sempre na condição de sombra. Considerando que no clima em análise o desconforto predominante é por calor, optou-se por realizar as medições na sombra, sabendo-se que a exposição direta ao sol resultaria em um grande percentual de entrevistados na condição de desconforto. Assim, optou-se por identificar as condições de conforto excluindo-se a radiação solar direta, já que esta variável é determinante no desconforto no clima quente e úmido.

\section{Entrevistas com os usuários}

Foram aplicados 900 questionários, sendo 450 no período seco e 450 no período úmido. Para construção dos questionários e definição do tamanho da amostra tomou-se por base estudos similares realizados por Nikolopolou e Lykoudis (2006) e Ng e Cheng (2012). A aplicação dos questionários foi realizada simultaneamente com o monitoramento microclimático. As medições e as entrevistas ocorreram no ano de 2015, o período seco corresponde aos meses de março e abril; o período úmido aos meses de julho e agosto.

\section{Figura 1 - Localização do Parque Zoobotânico Arruda Câmara}

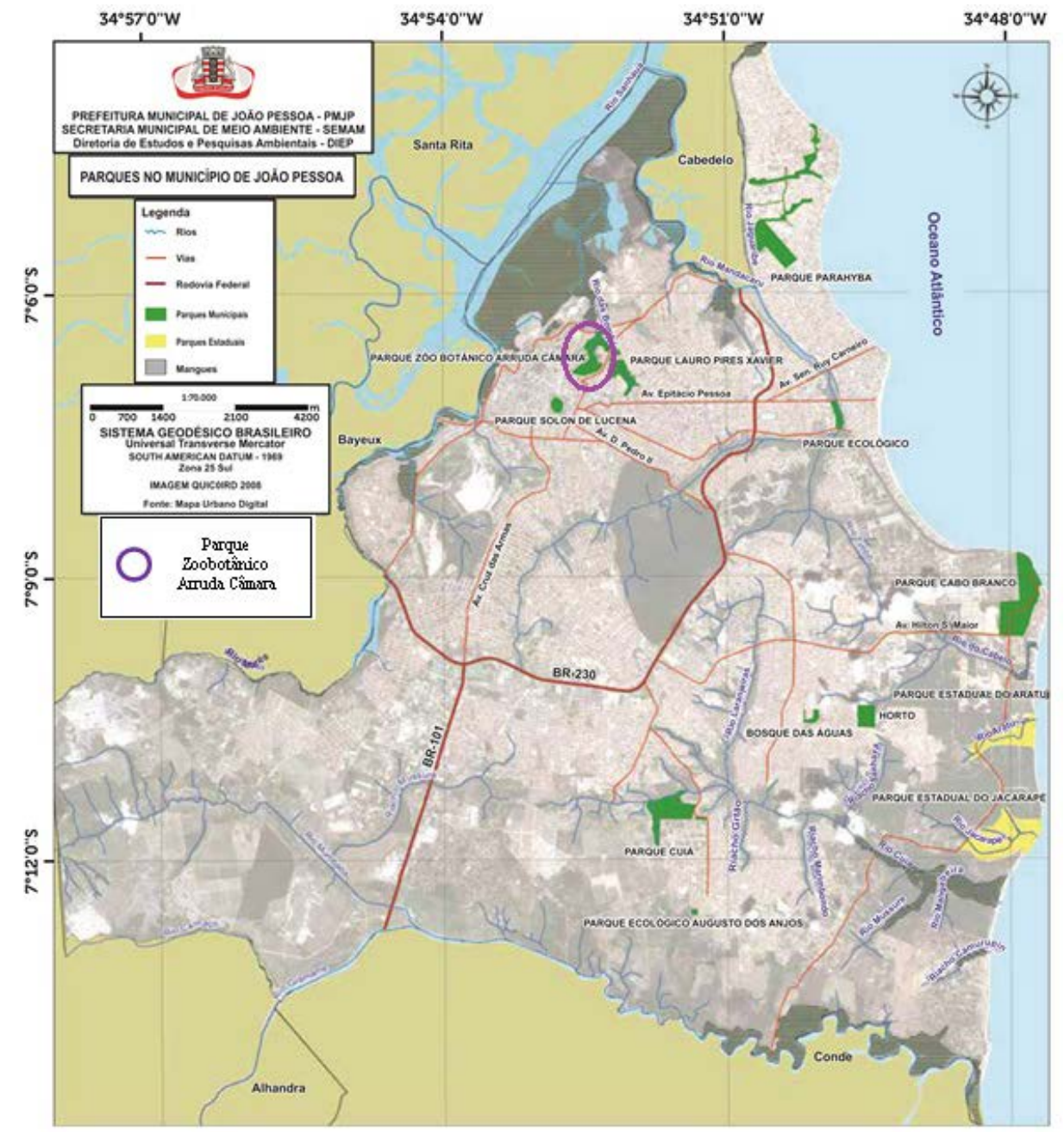

Fonte: adaptado de J oão Pessoa (2012). 
Quadro 1- Descrição dos dias de monitoramento microclimático

\begin{tabular}{|l|l|l|l|l|}
\hline Estação & Horário das medições & \multicolumn{1}{|c|}{ Dias de Coleta } & Total & \multicolumn{1}{|c|}{$\begin{array}{l}\text { Condição } \\
\text { Climática }\end{array}$} \\
\hline Seca & $09: 00$ às 16:00 & $\begin{array}{l}10,11,12,13,14,17,18,19, \\
21,26,28 \text { de março e 11 de abril }\end{array}$ & 12 dias & $\begin{array}{l}\text { Céu limpo, sem } \\
\text { precipitação }\end{array}$ \\
\hline Úmida & $09: 00$ às 16:00 & $\begin{array}{l}\text { 18, 19, de julho; 08, 15, 16, 22, } \\
23,28,29 \text { e 30 de agosto }\end{array}$ & 10 dias & $\begin{array}{l}\text { Céu limpo, sem } \\
\text { precipitação }\end{array}$ \\
\hline
\end{tabular}

Figura 2 - Posto de medições das variáveis ambientais: visão lateral (a) e obstrução do céu (b)

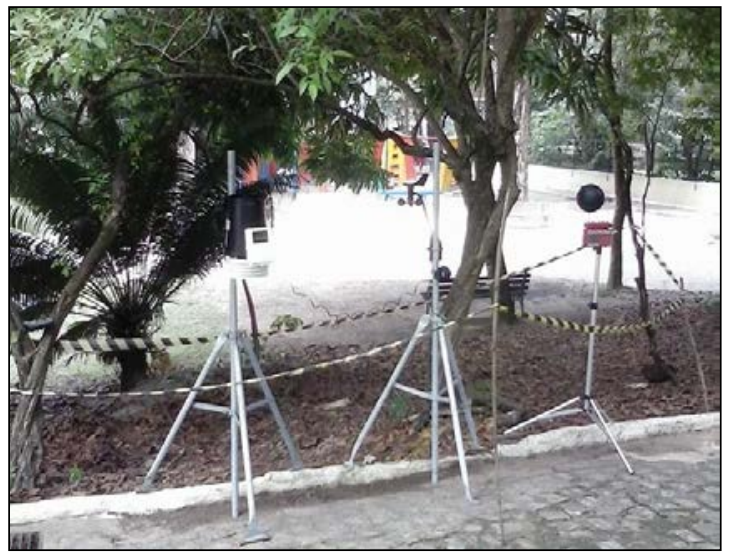

(a)

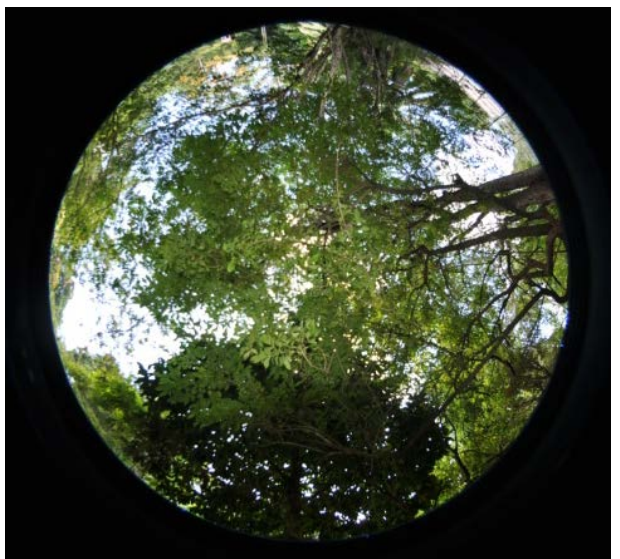

(b)

Figura 3 - Vista de topo do local das medições ambientais e aplicação dos questionários

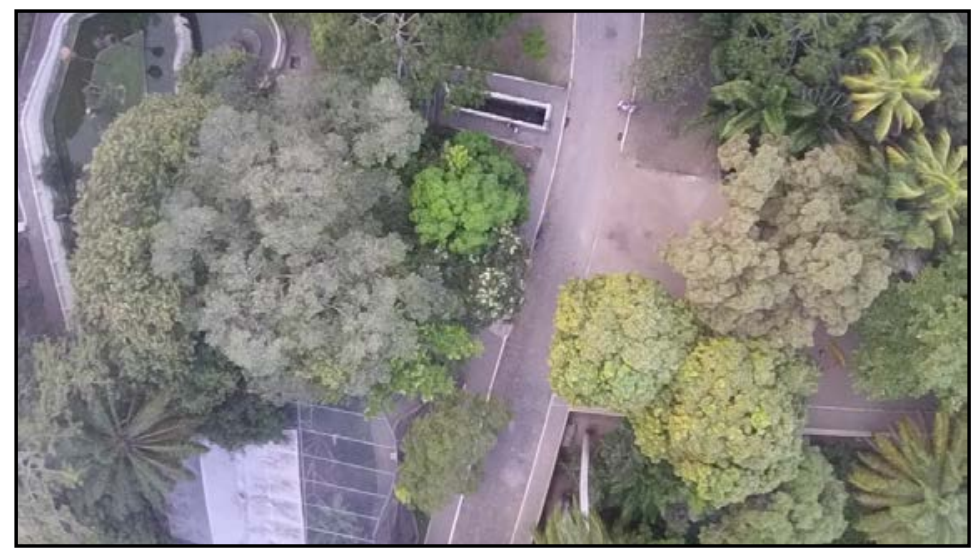

Os entrevistados foram escolhidos aleatoriamente objetivando a homogeneidade da amostra. As entrevistas duraram de 3 a 5 minutos. Os questionários foram organizados em três blocos. O primeiro bloco aborda informações pessoais referentes à idade, gênero, classificação da vestimenta, data, horário de início e fim da entrevista. Para a classificação da vestimenta utilizou-se a seguinte categorização:

(a) cabeça: chapéu, boné, lenço;

(b) corpo: vestido, camisa, camiseta de malha, blusa meia manga;

(c) pernas: calça, bermuda, shorts, saia; e (d) pés: tênis, sandália, sapato, meia.

Para cada categoria de vestimenta foi agregado um valor em CLO (Clothing) tomando por base a norma ISO7730 (INTERNATIONAL..., 2005). O segundo bloco aborda questões referentes à aclimatação e naturalidade (Quadro 2). O terceiro bloco compreende 8 questões relacionadas com a sensação, condição e preferência térmica dos visitantes (Quadro 3). As possibilidades de respostas estão presentes no Quadro 4. É importante destacar que na pergunta de número 6 , foi explicado aos entrevistados que a questão se referia ao conforto térmico em relação ao microclima do parque, e não em relação à estrutura física ou de serviços do local. 
Quadro 2 - Perguntas e respostas referentes à aclimatação e naturalidade

\begin{tabular}{|l|l|}
\hline \multicolumn{1}{|c|}{ Pergunta } & \multicolumn{1}{|c|}{ Resposta } \\
\hline Você é natural de João Pessoa? & Sim ( ) Não ( ) \\
\hline De onde ? & Nordeste ( ) outros ( ) \\
\hline $\begin{array}{l}\text { Você está em João Pessoa há mais de seis } \\
\text { meses? }\end{array}$ & Sim ( ) Não ( ) \\
\hline Há quanto tempo? & Dias ( ) Semanas ( ) Meses ( ) Anos ( ) Sim ( ) Não ( ) \\
\hline Nos últimos 15 minutos você estava em um ambiente com ar-condicionado?
\end{tabular}

Quadro 3- Perguntas sobre sensação, condição e preferência térmica

\begin{tabular}{|c|c|c|}
\hline Item & Variável observada & Descrição da pergunta \\
\hline 01 & Sensação térmica & Como você está se sentindo em relação ao calor? \\
\hline 02 & Exposição ao sol & $\begin{array}{l}\text { O entrevistado está ou esteve submetido à radiação nos últimos } \\
\text { minutos? }\end{array}$ \\
\hline 04 & $\begin{array}{l}\text { Sensação em relação ao } \\
\text { vento }\end{array}$ & Como você se sente em relação ao vento? \\
\hline 05 & $\begin{array}{l}\text { Sensação em relação à } \\
\text { umidade }\end{array}$ & Como você se sente em relação à umidade da sua pele? \\
\hline 06 & $\begin{array}{l}\text { Conforto térmico em relação } \\
\text { ao local }\end{array}$ & $\begin{array}{l}\text { Em termos gerais, como você se sente em relação a esse } \\
\text { espaço? }\end{array}$ \\
\hline 07 & Preferência térmica & Nesse momento, você preferia que estivesse? \\
\hline 08 & Sensação sobre a vestimenta & Você considera sua vestimenta? \\
\hline
\end{tabular}

Quadro 4 - Possibilidade de respostas dos questionamentos

\begin{tabular}{|c|c|c|c|c|c|}
\hline Item & Resposta & Valor & Item & Resposta & Valor \\
\hline 01 & $\begin{array}{c}\text { Muito frio } \\
\text { Frio } \\
\text { Um pouco frio } \\
\text { Neutro } \\
\text { Um pouco de calor } \\
\text { Calor } \\
\text { Muito calor }\end{array}$ & $\begin{array}{l}1 \\
2 \\
3 \\
4 \\
5 \\
6 \\
7\end{array}$ & 05 & $\begin{array}{c}\text { Seca } \\
\text { Neutra } \\
\text { Úmida - pouco desconfortável } \\
\text { Úmida - muito desconfortável }\end{array}$ & $\begin{array}{l}1 \\
2 \\
3 \\
4\end{array}$ \\
\hline 02 & $\begin{array}{l}\text { Sim } \\
\text { Não }\end{array}$ & $\begin{array}{l}0 \\
1\end{array}$ & 06 & $\begin{array}{c}\text { Confortável } \\
\text { Pouco desconfortável } \\
\text { Desconfortável } \\
\text { Muito desconfortável }\end{array}$ & $\begin{array}{l}1 \\
2 \\
3 \\
4\end{array}$ \\
\hline 03 & $\begin{array}{c}\text { Neutro } \\
\text { Pouco desconfortável } \\
\text { Desconfortável } \\
\text { Muito desconfortável }\end{array}$ & $\begin{array}{l}1 \\
2 \\
3 \\
4\end{array}$ & 07 & $\begin{array}{c}\text { Muito mais frio } \\
\text { Mais frio } \\
\text { Um pouco mais frio } \\
\text { Sem mudanças } \\
\text { Um pouco mais de calor } \\
\text { Mais calor } \\
\text { Muito mais calor }\end{array}$ & $\begin{array}{l}1 \\
2 \\
3 \\
4 \\
5 \\
6 \\
7\end{array}$ \\
\hline 04 & $\begin{array}{c}\text { Ventando muito } \\
\text { Ventando } \\
\text { Ventando levemente } \\
\text { Ventilado } \\
\text { Pouco ventilado } \\
\text { Insuficiente } \\
\text { Parado completamente }\end{array}$ & $\begin{array}{l}1 \\
2 \\
3 \\
4 \\
5 \\
6 \\
7\end{array}$ & 08 & $\begin{array}{c}\text { Fria } \\
\text { Neutra } \\
\text { Quente }\end{array}$ & $\begin{array}{l}1 \\
2 \\
3\end{array}$ \\
\hline
\end{tabular}




\section{Tratamento e análise dos dados}

As variáveis microclimáticas e os dados dos questionários foram digitalizados e organizados em planilhas Excel. As análises estatísticas foram realizadas através do software Statistica 7.0 da empresa StatSoft Inc ${ }^{\circledR}$ (2004). A temperatura de globo foi utilizada no cálculo da temperatura radiante média, por sua vez, calculada através da equação de convecção natural recomendada pela norma ISO 7726 (INTERNATIONAL..., 1998) (Eq. 1). A temperatura radiante média representa a temperatura uniforme de um ambiente. Para verificar se a sensação térmica real dos entrevistados (ASV) estava de acordo com a preferência térmica, as duas variáveis foram analisadas sob o ponto de vista contingencial através de uma planilha eletrônica dinâmica. A correlação de Spearman foi aplicada para analisar a relação entre as variáveis quantitativas (microclimáticas) e qualitativas (conforto térmico).

A medida de tamanho de efeito usado para explicar a relação entre sensação térmica e as variáveis ambientais foi a razão da chance (odds ratio), estimada a partir de um modelo de regressão logística ordinal. O modelo explica a chance de um entrevistado alegar que o ambiente gerou uma sensação térmica igual ou inferior a um certo nível térmico $j$ (esse nível térmico pode ser qualquer dos sete níveis entre "muito frio" e "muito quente"). O evento de interesse no modelo é a sensação térmica do indivíduo passar para um nível mais baixo, ou seja, o indivíduo sentir o ambiente mais frio. $\mathrm{O}$ modelo geral foi explicitado através das equações 2 a 7 que diferem entre si apenas pelo intercepto, sendo que a razão da chance em todas as equações mostra o quanto aumenta ou diminui a chance da sensação térmica passar para uma categoria inferior, neste caso menos aquecido que $j$. Foram utilizados gráficos de dispersão tipo bolha para delimitar o intervalo microclimático com maior concentração dos votos de sensação térmica em condição de neutralidade. $\mathrm{O}$ tamanho da bolha indica a frequência e posição dos votos da sensação térmica real sobre cada variável microclimática. O eixo (y) representa as categorias de sensação térmica: 1 Muito frio, 2 - Frio, 3-Pouco frio, 4 - Neutro, 5 Pouco calor, 6 - Calor e 7 - Muito calor. As categorias 1 e 2 foram consideradas desconforto térmico para o frio, as categorias 3,4 e 5 correspondem a neutralidade, 6 e 7 correspondem ao desconforto para o calor. O eixo (x) corresponde as variáveis microclimáticas (temperatura do ar, temperatura do globo, temperatura radiante média, velocidade do ar, radiação solar e umidade relativa do ar). Os índices de conforto PMV, PET e SET foram calculados através do software Rayman 2.0 (MATZARAKIS; RUTZ, 2010).

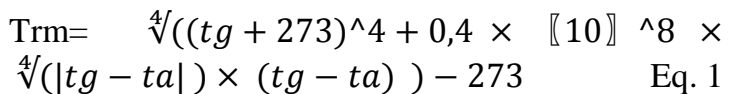

Onde:

trm = temperatura radiante média;

$\operatorname{tg}$ = temperatura do globo; e

ta $=$ temperatura do ar.

Chance $=(S T \leq J)=$

$e^{\beta 0 j} \cdot\left(e^{\beta 1}\right)^{T a} \cdot\left(e^{\beta 2}\right)^{V a} \cdot\left(e^{\beta 3}\right)^{T r m} \cdot\left(e^{\beta 4}\right)^{R H} \cdot\left(e^{\beta 5}\right)^{R S} \quad$ Eq. 2

Chance $=(S T \leq 2)=$

$e^{-0,306} \cdot\left(e^{-0,306}\right)^{T a}\left(e^{-0,409}\right)^{V a} \cdot\left(e^{-2,42}\right)^{T r m} \cdot\left(e^{0,011}\right)^{R H} \cdot\left(e^{-0,001}\right)^{R S}$

Eq. 3

Chance $=(S T \leq 3)=$

$e^{-0,409} \cdot\left(e^{-0,306}\right)^{T a} \cdot\left(e^{-0,409}\right)^{V a} \cdot\left(e^{-2,42}\right)^{T r m} \cdot\left(e^{0,011}\right)^{R H} \cdot\left(e^{-0,001}\right)^{R S}$

Eq. 4

Chance $=(S T \leq 4)=$ $e^{-2,42} \cdot\left(e^{-0,306}\right)^{T a} \cdot\left(e^{-0,409}\right)^{V a} \cdot\left(e^{-2,42}\right)^{T r m} \cdot\left(e^{0,011}\right)^{R H} \cdot\left(e^{-0,001}\right)^{R S}$

Eq. 5

Chance $=(S T \leq 5)=$ $e^{0,011} \cdot\left(e^{-0,306}\right)^{T a} \cdot\left(e^{-0,409}\right)^{V a} \cdot\left(e^{-2,42}\right)^{T r m} \cdot\left(e^{0,011}\right)^{R H} \cdot\left(e^{-0,001}\right)^{R S}$

Eq. 6

Chance $=(S T \leq 6)=$ $e^{-0,001} \cdot\left(e^{-0,306}\right)^{T a} \cdot\left(e^{-0,409}\right)^{V a} \cdot\left(e^{-2,42}\right)^{T r m} \cdot\left(e^{0,011}\right)^{R H} \cdot\left(e^{-0,001}\right)^{R S}$

Onde:

ST = Sensação térmica;

$\mathrm{J}=$ Categorias de 2 a 6;

Chance $=$ Probabilidade de ocorrência de um evento;

Trm = Temperatura radiante média;

Ta = Temperatura do ar;

Va = Velocidade do ar;

$\mathrm{RH}=$ Umidade relativa do ar; $\mathrm{e}$

RS = Radiação Solar.

\section{Resultados e Discussões}

Os resultados estão apresentados ordenadamente da seguinte forma:

(a) descrições das variáveis ambientais;

(b) descrições das variáveis pessoais e demográficas;

(c) sensação térmica;

(d) sensação e preferência térmica; 
(e) correlação entre variáveis ambientais e sensação térmica;

(f) modelo de regressão logística ordinal;

(g) intervalo de conforto térmico; e

(h) intervalo de conforto para PMV, PET e SET.

\section{Descrições das variáveis ambientais}

No período seco a média da temperatura do ar foi 2 ${ }^{\circ} \mathrm{C}$ mais elevada que o período úmido, com máxima de $31{ }^{\circ} \mathrm{C}$. Houve pouca variação da umidade relativa do ar, em torno de $60 \%$. Os níveis de ventilação foram reduzidos, com média de $0,4 \mathrm{~m} / \mathrm{s}$ e máxima de $1,3 \mathrm{~m} / \mathrm{s}$.

Os resultados apresentaram intensa relação com as condições climáticas da cidade estudada, a temperatura média anual se mantém em torno dos $28{ }^{\circ} \mathrm{C}$ com amplitude máxima de até $5{ }^{\circ} \mathrm{C}$. A descrição completa do monitoramento microclimático está apresentada na Tabela 1.

\section{Descrições das variáveis pessoais e demográficas}

Considerando os dois períodos de medição (seco e úmido) 54\% dos visitantes pertenciam ao gênero feminino e $46 \%$ ao gênero masculino.

A maior parte dos entrevistados tinha entre 21 e 30 anos. Dos entrevistados, 58\% eram naturais de João Pessoa e 93\% da região nordeste.

Grande parte, 73\% dos indivíduos estavam em João Pessoa há mais de 6 meses e 80\% estavam em ambiente com condições naturais até 15 minutos antes da entrevista.

A ação mais desenvolvida nos 15 minutos anteriores à entrevista foi caminhar com 57\%. A descrição completa das variáveis pessoais está apresentada na Tabela 2.

\section{Sensação térmica}

Levando em consideração todo o período de coleta, no que se refere à sensação térmica destaca-se que:

(a) 353 entrevistados sentiram-se neutros em relação ao calor;

(b) 403 sentiram-se neutros em relação à exposição solar; e

(c) 773 pessoas consideraram o local termicamente confortável (Tabela 3).

Em relação a preferência térmica: 414 entrevistados não relataram desejo de mudança na condição térmica, enquanto 370 gostariam que estivesse um pouco mais frio. É possível perceber que a maior parte dos entrevistados estava em conforto ou leve desconforto para o calor e não relataram desejo de alteração na condição térmica, mesmo com a ventilação reduzida e a temperatura do ar em torno de $28{ }^{\circ} \mathrm{C}$. Sendo plausível deduzir que as pessoas, em grande parte, estão adaptadas ao clima local. A satisfação com o microclima do parque também pode influenciar na sensação termica dos visitantes, a presença da vegetação de porte arbóreo resulta em grandes áreas sombreadas e reduz a incidência solar direta sobre as pessoas.

\section{Sensação e preferência térmica}

Com a interseção entre a sensação e preferência térmica (Tabela 4) observa-se que dos 39\% dos entrevistados (coluna azul) que se sentiram neutros em relação ao "calor”, apenas 25\% não gostariam de mudar as condições climáticas; dos 14\% restantes, $13 \%$ gostariam que o ambiente térmico estivesse um pouco mais frio e apenas $1 \%$ gostaria que o ambiente térmico estivesse mais quente.

Dos $46 \%$ dos entrevistados que não mudariam as condições climáticas do ambiente (linha azul), apenas 25\% estão na categoria neutra em relação ao calor, os outros $21 \%$ estão em categorias de desconforto para o calor.

Destaca-se ainda, na parte superior (em vermelho), que $43 \%$ dos entrevistados que sentem algum grau de desconforto para o calor, tem preferência por um ambiente térmico mais frio, confirmando o esperado. 
Tabela 1 - Descrição das variáveis ambientais

\begin{tabular}{c|l|l|l|l}
\hline \multicolumn{1}{c|}{ Variáveis climáticas } & Min/Med/Max/Dp & Período seco & Período úmido & Total \\
\hline \multirow{4}{*}{ 1-Temperatura do ar $\left({ }^{\circ} \mathrm{C}\right)$} & Mínima & 23,6 & 26,1 & 23,6 \\
& Média & 29,6 & 27,6 & 28,6 \\
& Máxima & 31,2 & 28,9 & 31,2 \\
& Desv. Pad & 1,04 & 0,6 & 1,3 \\
\hline \multirow{5}{*}{ 2-Umidade relativa do ar (\%) } & Mínima & 48 & 46 & 46 \\
& Média & 61 & 64 & 62 \\
& Máxima & 86 & 80 & 86 \\
& Desv. Pad & 8 & 8 & 8 \\
\hline \multirow{5}{*}{ 3-Velocidade do ar (m/s) } & Mínima & 0,0 & 0,0 & 0 \\
& Média & 0,2 & 0,4 & 0,3 \\
& Máxima & 1,3 & 1,3 & 1,3 \\
& Desv. Pad & 0,3 & 0,4 & 0,35 \\
\hline \multirow{3}{*}{ 4-Temperatura de globo ( $\left.{ }^{\circ} \mathrm{C}\right)$} & Mínima & 26,3 & 24,5 & 24,5 \\
& Média & 30,6 & 28,6 & 29,6 \\
& Máxima & 33,7 & 30,6 & 33,7 \\
& Desv. Pad & 1,1 & 0,9 & 1,5 \\
\hline \multirow{5}{*}{ 5-Radiação solar $\left(\mathrm{W} / \mathrm{m}^{2}\right)$} & Mínima & 9 & 6 & 6 \\
& Média & 57 & 44 & 50 \\
& Máxima & 250 & 258 & 258 \\
& Desv. Pad & 32 & 32 & 33 \\
\hline \multirow{5}{*}{ 6-Temp. radiante média $\left({ }^{\circ} \mathrm{C}\right)$} & Mínima & 25,3 & 24,0 & 23,3 \\
& Média & 31,0 & 28,9 & 29,9 \\
& Máxima & 35,0 & 31,5 & 35,4 \\
& Desv. Pad & 1,4 & 1,1 & 1,6 \\
\hline
\end{tabular}

Tabela 2 - Descrição das variáveis pessoais

\begin{tabular}{|c|c|c|c|c|}
\hline Variável & Resposta & Período seco & Período úmido & Total \\
\hline $\mathrm{N}$ & - & 450 & 450 & 900 \\
\hline \multirow{2}{*}{ Gênero } & Masculino & $48 \%$ & $44 \%$ & $46 \%$ \\
\hline & Feminino & $52 \%$ & $56 \%$ & $54 \%$ \\
\hline \multirow{6}{*}{ Idade } & 15 a 20 anos & $25 \%$ & $16 \%$ & $21 \%$ \\
\hline & 21 a 30 anos & $34 \%$ & $27 \%$ & $30 \%$ \\
\hline & 31 a 40 anos & $22 \%$ & $30 \%$ & $26 \%$ \\
\hline & 41 a 50 anos & $9 \%$ & $13 \%$ & $11 \%$ \\
\hline & 51 a 60 anos & $6 \%$ & $8 \%$ & $7 \%$ \\
\hline & + de 60 anos & $4 \%$ & $6 \%$ & $5 \%$ \\
\hline \multirow{2}{*}{ Naturalidade } & Local & $55 \%$ & $39 \%$ & $58 \%$ \\
\hline & Outras & $44 \%$ & $61 \%$ & $42 \%$ \\
\hline \multirow{2}{*}{ Naturalidade Região } & Local & $93 \%$ & $94 \%$ & $93 \%$ \\
\hline & Outras regiões & $7 \%$ & $6 \%$ & $7 \%$ \\
\hline \multirow{2}{*}{ Permanência no local } & + de 6 meses & $70 \%$ & $76 \%$ & $73 \%$ \\
\hline & - de 6 meses & $30 \%$ & $24 \%$ & $27 \%$ \\
\hline \multirow{3}{*}{ Permanência no local } & 4 Dias & $63 \%$ & $73 \%$ & $67 \%$ \\
\hline & Semana & $11 \%$ & $11 \%$ & $11 \%$ \\
\hline & Mês & $26 \%$ & $16 \%$ & $22 \%$ \\
\hline \multirow{2}{*}{ Ambiente anterior } & Natural & $77 \%$ & $84 \%$ & $80 \%$ \\
\hline & Climatizado & $22 \%$ & $16 \%$ & $20 \%$ \\
\hline \multirow{6}{*}{ Atividade } & Caminhando & $57 \%$ & $56 \%$ & $57 \%$ \\
\hline & Sentado & $26 \%$ & $24 \%$ & $25 \%$ \\
\hline & De pé, parado & $7 \%$ & $7 \%$ & $7 \%$ \\
\hline & De pé, em atividade & $2 \%$ & $4 \%$ & $3 \%$ \\
\hline & Dirigindo & $8 \%$ & $9 \%$ & $8 \%$ \\
\hline & Correndo/jogando & $0 \%$ & $0 \%$ & $0 \%$ \\
\hline
\end{tabular}


Tabela 3 - Descrição das variáveis qualitativas

\begin{tabular}{|c|c|c|c|c|c|}
\hline Variável & Resposta & $\begin{array}{l}\text { Período } \\
\text { seco }\end{array}$ & $\begin{array}{c}\text { Período } \\
\text { Úmido }\end{array}$ & Total & Média \\
\hline $\mathrm{N}$ & - & 450 & 450 & 900 & \\
\hline \multirow{7}{*}{ Sensação térmica } & \multirow{2}{*}{$\begin{array}{l}\text { Muito Frio } \\
\text { Frio }\end{array}$} & 0 & 0 & 0 & 0 \\
\hline & & 0 & 0 & 0 & 0 \\
\hline & Um pouco de frio & 6 & 8 & 14 & 7 \\
\hline & Neutro & 137 & 216 & 353 & 176,5 \\
\hline & Um pouco de calor & 134 & 131 & 265 & 132,5 \\
\hline & Calor & 62 & 50 & 112 & 56 \\
\hline & Muito calor & 111 & 45 & 156 & 78 \\
\hline \multirow{2}{*}{$\begin{array}{l}\text { Exposição à radiação } \\
\text { solar }\end{array}$} & Sim & 287 & 228 & 515 & 257,5 \\
\hline & Não & 163 & 222 & 385 & 192,5 \\
\hline \multirow{4}{*}{$\begin{array}{l}\text { Sensação em relação } \\
\text { à radiação solar }\end{array}$} & Neutro & 206 & 197 & 403 & 201,5 \\
\hline & Pouco desconfortável & 107 & 119 & 226 & 113 \\
\hline & Desconfortável & 71 & 90 & 161 & 80,5 \\
\hline & Muito desconfortável & 66 & 44 & 110 & 55 \\
\hline \multirow{7}{*}{$\begin{array}{l}\text { Sensação em relação } \\
\text { à circulação do ar }\end{array}$} & Ventando muito & 1 & 6 & 7 & 3,5 \\
\hline & Ventando & 12 & 16 & 28 & 14 \\
\hline & Ventando levemente & 121 & 124 & 245 & 122,5 \\
\hline & Ventilado & 51 & 89 & 140 & 70 \\
\hline & Pouco Ventilado & 183 & 157 & 340 & 170 \\
\hline & Insuficiente & 29 & 22 & 51 & 25,5 \\
\hline & Parado Completamente & 53 & 36 & 89 & 44,5 \\
\hline \multirow{4}{*}{ Umidade da pele } & Seca & 27 & 38 & 65 & 32,5 \\
\hline & Neutra & 159 & 234 & 393 & 196,5 \\
\hline & Úmida & 216 & 154 & 370 & 185 \\
\hline & Excessiva & 48 & 24 & 72 & 36 \\
\hline \multirow{4}{*}{$\begin{array}{l}\text { Conforto térmico em } \\
\text { relação ao local }\end{array}$} & Confortável & 372 & 401 & 773 & 386,5 \\
\hline & Pouco desconfortável & 61 & 34 & 95 & 47,5 \\
\hline & Desconfortável & 14 & 13 & 27 & 13,5 \\
\hline & Muito desconfortável & 3 & 2 & 5 & 2,5 \\
\hline \multirow{7}{*}{ Preferência térmica } & Muito mais frio & 0 & 0 & 0 & 0 \\
\hline & Mais frio & 47 & 32 & 79 & 39,5 \\
\hline & Um pouco mais frio & 229 & 158 & 387 & 193,5 \\
\hline & Sem mudanças & 167 & 247 & 414 & 207 \\
\hline & Um pouco mais calor & 5 & 13 & 18 & 9 \\
\hline & Mais calor & 1 & 0 & 1 & 0,5 \\
\hline & Muito mais calor & 1 & 0 & 1 & 0,5 \\
\hline \multirow{3}{*}{$\begin{array}{l}\text { Avaliação térmica da } \\
\text { roupa }\end{array}$} & Fria & 62 & 53 & 115 & 57,5 \\
\hline & Neutra & 264 & 302 & 566 & 283 \\
\hline & Quente & 124 & 95 & 219 & 109,5 \\
\hline
\end{tabular}


Tabela 4 - Preferência térmica x Sensação térmica

\begin{tabular}{|c|c|c|c|c|c|c|c|c|}
\hline & \multicolumn{8}{|c|}{ Sensação Térmica } \\
\hline $\begin{array}{c}\text { Preferência } \\
\text { Térmica }\end{array}$ & $\begin{array}{l}\text { Muito } \\
\text { frio }\end{array}$ & Frio & $\begin{array}{l}\text { Um pouco } \\
\text { de frio }\end{array}$ & Neutro & $\begin{array}{l}\text { Um pouco } \\
\text { de calor }\end{array}$ & Calor & $\begin{array}{l}\text { Muito } \\
\text { Calor }\end{array}$ & Total \\
\hline \multirow[t]{2}{*}{ Muito mais frio } & 0,0 & 0,0 & 0,0 & 0,0 & 0,0 & 0,0 & 0,0 & 0,0 \\
\hline & $0,0 \%$ & $0,0 \%$ & $0,0 \%$ & $0,0 \%$ & $0,0 \%$ & $0,0 \%$ & $0,0 \%$ & $0,0 \%$ \\
\hline \multirow[t]{2}{*}{ Mais frio } & 0 & 0 & 2 & 13 & 27 & 11 & 26 & 79 \\
\hline & $0 \%$ & $0 \%$ & $0 \%$ & $1 \%$ & $3 \%$ & $1 \%$ & $3 \%$ & $9 \%$ \\
\hline \multirow[t]{2}{*}{ Um pouco mais de frio } & 0 & 0 & 3 & 106 & 132 & 64 & 82 & 387 \\
\hline & $0,0 \%$ & $0,0 \%$ & $0,3 \%$ & $11,8 \%$ & $14,7 \%$ & $7,1 \%$ & $9,1 \%$ & $43,0 \%$ \\
\hline \multirow{2}{*}{ Sem mudanças } & 0 & 0 & 7 & 228 & 99 & 34 & 46 & 414 \\
\hline & $0,0 \%$ & $0,0 \%$ & $0,8 \%$ & $25,3 \%$ & $11,0 \%$ & $3,8 \%$ & $5,1 \%$ & $46,0 \%$ \\
\hline \multirow{2}{*}{ Um pouco mais de calor } & 0 & 0 & 2 & 5 & 6 & 3 & 2 & 18 \\
\hline & $0,0 \%$ & $0,0 \%$ & $0,2 \%$ & $0,6 \%$ & $0,7 \%$ & $0,3 \%$ & $0,2 \%$ & $2,0 \%$ \\
\hline \multirow[t]{2}{*}{ Mais calor } & 0 & 0 & 0 & 1 & 0 & 0 & 0 & 1 \\
\hline & $0,0 \%$ & $0,0 \%$ & $0,0 \%$ & $0,1 \%$ & $0,0 \%$ & $0,0 \%$ & $0,0 \%$ & $0,1 \%$ \\
\hline \multirow[t]{2}{*}{ Muito mais calor } & 0 & 0 & 0 & 0 & 1 & 0 & 0 & 1 \\
\hline & $0,0 \%$ & $0,0 \%$ & $0,0 \%$ & $0,0 \%$ & $0,1 \%$ & $0,0 \%$ & $0,0 \%$ & $0,1 \%$ \\
\hline \multirow[t]{2}{*}{ Total } & 0 & 0 & 14 & 353 & 265 & 112 & 156 & 100 \\
\hline & $0,0 \%$ & $0,0 \%$ & $1,6 \%$ & $39,2 \%$ & $29,4 \%$ & $12,4 \%$ & $17,3 \%$ & $100,0 \%$ \\
\hline
\end{tabular}

\section{Correlação entre variáveis ambientais e qualitativas}

Verificou-se a normalidade das variáveis ambientais e qualitativas através do teste Kolmorogov-Smirnov $\mathrm{p}<0,05$. Não havendo normalidade, optou-se por utilizar a correlação de Spearman ao nível de significância de 95\%. A sensação térmica, umidade da pele e preferência térmica foram as variáveis qualitativas que mais se correlacionaram com as variáveis ambientais temperatura do ar, temperatura do globo, temperatura radiante média e umidade relativa do ar (Tabela 5). De modo geral, as correlações entre os grupos de variáveis analisados foram baixas $(\mathrm{r}=0,2)$. Apenas uma variável microclimática não é suficiente para explicar a sensação, preferência e condição térmica dos visitantes. Ainda assim, as variáveis microclimáticas: temperatura do ar, temperatura do globo, temperatura radiante média foram as variáveis que mais influenciaram na sensação, preferência e condição térmica dos visitantes. Valores de $\mathrm{r}=0,2$ também foram observados por Rossi, Kruger e Brode (2012), através da análise multivariada as correlações igualmente não foram suficientes para explicar a sensação térmica. Pesquisas desse tipo apresentam elevada subjetividade, com influência de aspectos físicos, fisiológicos e psicológicos (NIKOLOPOULOU; STEEMERS, 2003). Ainda assim, ressalta-se que muitas correlações apresentaram significância estatística $(p=, 000)$ (destacadas em vermelho nas tabelas a seguir).

\section{Modelo de regressão logística ordinal}

Modelos matemáticos são importantes aliados na predição do conforto térmico. Utilizando de regressão logística Rossi, Kruger e Brode (2012) propõe um modelo capaz de predizer $65 \%$ dos casos de ocorrência da sensação térmica para população em Curitiba-PR. Buscando-se evitar variáveis correlacionadas no mesmo modelo foi realizada previamente uma correlação de Spearman ao nível de significância de $95 \%$ entre as variáveis ambientais. Todas as variáveis microclimáticas apresentaram correlações entre si, exceto a velocidade do ar que obteve correlações baixas (Tabela 6). A partir dos resultados encontrados nas correlações significativas entre as variáveis, verificou-se através de modelagem matemática o efeito das variáveis ambientais sobre a sensação térmica. Primeiramente os efeitos das variáveis microclimáticas sobre a sensação térmica foram testados de forma independente, como mostra a Tabela 7. Foram encontrados efeitos significativos para temperatura do ar, temperatura radiante média e velocidade do ar $(\mathrm{p}=0,000)$. A umidade do ar $(p=0,146)$ e radiação solar ( $p=0,260)$ não obtiveram efeitos significativos. O valor da razão da chance (odds ratio) indica que quando temperatura do ar aumenta em uma unidade, as chances da sensação térmica passar para uma categoria menos quente diminuem em 27\%. Quando a temperatura radiante média aumenta em $1{ }^{\circ} \mathrm{C}$ o comportamento é semelhante, o valor da chance de 0,78 mostra que as chances da sensação térmica passar para uma categoria menos quente diminuem em $22 \%$; já para a velocidade do ar o efeito é inverso, o valor da razão da chance de 1,64 indica que a medida que a 
velocidade do ar aumenta a cada $1 \mathrm{~m} / \mathrm{s}$ as chances da sensação térmica passar para uma categoria menos quente aumentam em 64\%. Sabendo que a velocidade do ar não obteve correlação com nenhuma das outras variáveis climáticas e que a temperatura do ar e temperatura radiante média estão correlacionadas, foi possível combinar duas variáveis climáticas não correlacionadas em um mesmo modelo. A correlação entre a temperatura do ar e temperatura radiante média provavelmente deve-se ao fato de que o local da entrevista, apesar de ser sombreado por árvores, não é totalmente opaco à radiação solar direta (variável conforme a posição do sol). Nos dias com sol a temperatura radiante média tende a ser maior, nos dias nublados será menor, assim, há variação na temperatura radiante média, influencia na sensação térmica dos visitantes. Tendo em vista que a temperatura do ar eleva-se a partir do contato com as superfícies aquecidas do entorno é compreensível que a mesma tenha correlação com a temperatura radiante média. Na Tabela 6 pode-se observar a combinação das variáveis: temperatura do ar e velocidade do ar; e da temperatura radiante média com a velocidade do ar. Ambos os modelos combinados apresentam efeitos significativos $(\mathrm{p}<0,05)$. Quando a temperatura do ar e a velocidade do ar foram combinadas em um mesmo modelo o valor da razão da chance de 0,74 mostra que a medida que a temperatura do ar aumenta em $1{ }^{\circ} \mathrm{C}$, as chances de um indivíduo passar para uma categoria menos quente diminuem em $26 \%$, já a o valor da chance de 1,48 mostra que à medida que a velocidade do ar aumenta em $1 \mathrm{~m} / \mathrm{s}$ as chances de um indivíduo passar para uma categoria menos quente aumentam em $48 \%$. Quando a temperatura radiante média e a velocidade do ar foram combinadas em um só modelo os resultados seguiram a mesma tendência, com o valor de 0,78 indicando que à medida que a temperatura radiante média aumenta em uma unidade, as chances de um indivíduo passar para uma categoria menos quente diminuem em 22\%, já o valor da chance de 1,74 mostra que à medida que a velocidade do ar aumenta em $1 \mathrm{~m} / \mathrm{s}$ as chances de um indivíduo passar para uma categoria menos quente aumentam em $74 \%$. As Tabelas 7 e 8 indicam as estimativas e os resultados dos testes de significância dos parâmetros do modelo de regressão. O resultado do teste é apresentado por meio da estatística de teste e do valor p. Ambas as medidas indicam necessariamente conclusões similares. Sempre que a estatística de teste está entre -2 e 2 tem-se o parâmetro como não significativo e o valor p será superior a 0,05.

Tabela 5 - Correlação entre as variáveis qualitativas e ambientais

\begin{tabular}{|c|c|c|c|c|c|c|}
\hline \multicolumn{7}{|c|}{ Correlação de Spearman para significância de $p<0,05$} \\
\hline $\begin{array}{l}\text { Variável } \\
\text { climática }\end{array}$ & $\begin{array}{l}\text { Temperatura } \\
\text { do ar }{ }^{\circ} \mathrm{C}\end{array}$ & $\begin{array}{l}\text { Umidade } \\
\text { do ar } \%\end{array}$ & $\begin{array}{c}\text { Velocidade } \\
\text { do ar m/s }\end{array}$ & $\begin{array}{l}\text { Radiação } \\
\text { solar W/m² }\end{array}$ & $\begin{array}{l}\text { Temperatura } \\
\text { de globo }{ }^{\circ} \mathrm{C}\end{array}$ & $\begin{array}{c}\text { Temperatura } \\
\text { radiante } \\
\text { média }{ }^{\circ} \mathrm{C}\end{array}$ \\
\hline $\begin{array}{l}\text { Sensação de } \\
\text { calor }\end{array}$ & $\begin{array}{c}0,212 \\
p=, 000\end{array}$ & $\begin{array}{c}0,040 \\
p=, 271\end{array}$ & $\begin{array}{l}-0,095 \\
p=, 007\end{array}$ & $\begin{array}{c}0,083 \\
p=, 231\end{array}$ & $\begin{array}{c}0,215 \\
p=, 000\end{array}$ & $\begin{array}{c}0,208 \\
p=, 000\end{array}$ \\
\hline $\begin{array}{l}\text { Exposição à } \\
\text { radiação }\end{array}$ & $\begin{array}{l}-0,228 \\
p=, 000\end{array}$ & $\begin{array}{c}0,261 \\
p=, 000\end{array}$ & $\begin{array}{l}-0,013 \\
p=, 904\end{array}$ & $\begin{array}{l}-0,173 \\
p=, 000\end{array}$ & $\begin{array}{l}-0,243 \\
p=, 000\end{array}$ & $\begin{array}{l}-0,232 \\
p=, 000\end{array}$ \\
\hline $\begin{array}{l}\text { Exposição } \\
\text { ao sol }\end{array}$ & $\begin{array}{c}0,130 \\
p=, 000\end{array}$ & $\begin{array}{l}-0,181 \\
p=, 000\end{array}$ & $\begin{array}{l}-0,047 \\
p=, 251\end{array}$ & $\begin{array}{c}0,104 \\
p=, 000\end{array}$ & $\begin{array}{c}0,155 \\
p=, 000\end{array}$ & $\begin{array}{c}0,162 \\
p=, 000\end{array}$ \\
\hline $\begin{array}{l}\text { Sensação do } \\
\text { vento }\end{array}$ & $\begin{array}{c}0,026 \\
p=, 509\end{array}$ & $\begin{array}{c}0,070 \\
p=, 009\end{array}$ & $\begin{array}{l}-0,038 \\
p=, 379\end{array}$ & $\begin{array}{c}0,059 \\
p=, 307\end{array}$ & $\begin{array}{c}0,040 \\
p=, 103\end{array}$ & $\begin{array}{c}0,045 \\
p=, 084\end{array}$ \\
\hline $\begin{array}{l}\text { Umidade da } \\
\text { pele }\end{array}$ & $\begin{array}{c}0,204 \\
p=, 000\end{array}$ & $\begin{array}{l}-0,048 \\
p=, 015\end{array}$ & $\begin{array}{l}-0,006 \\
p=, 851\end{array}$ & $\begin{array}{c}0,101 \\
p=, 139\end{array}$ & $\begin{array}{c}0,189 \\
p=, 000\end{array}$ & $\begin{array}{c}0,171 \\
p=, 000\end{array}$ \\
\hline $\begin{array}{l}\text { Sensação } \\
\text { térmica }\end{array}$ & $\begin{array}{c}0,081 \\
p=, 039\end{array}$ & $\begin{array}{c}0,052 \\
p=, 129\end{array}$ & $\begin{array}{c}0,001 \\
p=, 855\end{array}$ & $\begin{array}{c}0,041 \\
p=, 825\end{array}$ & $\begin{array}{c}0,078 \\
p=, 023\end{array}$ & $\begin{array}{c}0,075 \\
p=, 030\end{array}$ \\
\hline $\begin{array}{l}\text { Preferência } \\
\text { térmica }\end{array}$ & $\begin{array}{l}-0,213 \\
p=, 000\end{array}$ & $\begin{array}{c}0,095 \\
p=, 005\end{array}$ & $\begin{array}{c}0,051 \\
p=, 181\end{array}$ & $\begin{array}{l}-0,073 \\
p=, 036\end{array}$ & $\begin{array}{l}-0,210 \\
p=, 000\end{array}$ & $\begin{array}{l}-0,202 \\
p=, 000\end{array}$ \\
\hline $\begin{array}{l}\text { Sensação } \\
\text { calor roupa }\end{array}$ & $\begin{array}{c}0,066 \\
p=, 030\end{array}$ & $\begin{array}{l}-0,028 \\
p=, 242\end{array}$ & $\begin{array}{l}-0,045 \\
p=, 241\end{array}$ & $\begin{array}{l}-0,007 \\
p=, 228\end{array}$ & $\begin{array}{c}0,067 \\
p=, 035\end{array}$ & $\begin{array}{c}0,057 \\
p=, 061\end{array}$ \\
\hline
\end{tabular}


Tabela 6 - Correlação entre as variáveis ambientais

\begin{tabular}{l|c|c|c|c|c}
\hline \multicolumn{6}{|c}{ Correlação de Sperman para significância de $\mathbf{p}<, \mathbf{0 5}$} \\
\hline Variável climática & $\begin{array}{c}\text { Temperatura } \\
\text { do ar }{ }^{\circ} \mathrm{C}\end{array}$ & $\begin{array}{c}\text { Umidade } \\
\text { do ar \% }\end{array}$ & $\begin{array}{c}\text { Velocidade } \\
\text { do ar } \mathrm{m} / \mathrm{s}\end{array}$ & $\begin{array}{c}\text { Radiação } \\
\text { solar W/m }{ }^{2}\end{array}$ & $\begin{array}{c}\text { Temperatura radiante } \\
\text { média }{ }^{\circ} \mathrm{C}\end{array}$ \\
\hline Temperatura do ar & 1,000 & $-0,634$ & $-0,088$ & 0,472 \\
${ }^{\circ} \mathrm{C}$ & $\mathrm{p}=---$ & $\mathrm{p}=0,00$ & $\mathrm{p}=, 002$ & 0,798 \\
\hline Umidade do ar \% & $-0,634$ & 1,000 & $-0,172$ & $-0,500$ & $\mathrm{p}=0,00$ \\
\hline Velocidade do ar & $\mathrm{p}=0,00$ & $\mathrm{p}=---$ & $\mathrm{p}=, 000$ & $\mathrm{p}=0,00$ & $-0,534$ \\
$\mathrm{~m} / \mathrm{s}$ & $-0,088$ & $-0,172$ & 1,000 & 0,091 & $\mathrm{p}=0,00$ \\
\hline Radiação solar & $\mathrm{p}=, 002$ & $\mathrm{p}=, 000$ & $\mathrm{p}=---$ & $\mathrm{p}=, 668$ & $-0,084$ \\
W/m & 0,472 & $-0,508$ & 0,091 & 1,000 & $\mathrm{p}=, 001$ \\
\hline Temp. radiante & $\mathrm{p}=, 000$ & $\mathrm{p}=0,00$ & $\mathrm{p}=, 668$ & $\mathrm{p}=---$ & 0,411 \\
média ${ }^{\circ} \mathrm{C}$ & 0,798 & $-0,534$ & $-0,084$ & 0,411 & $\mathrm{p}=, 000$ \\
\hline
\end{tabular}

Tabela 7 - Efeito independente das variáveis ambientais sobre a sensação térmica

Sensação térmica - estimativa dos parâmetros / Regressão logística ordinal

\begin{tabular}{l|l|l|l|l|l}
\hline Efeito Independente & Estimativa & Erro padrão & Test Wald & Razão da chance & Valor $\mathrm{p}$ \\
\hline Temperatura do $\operatorname{ar}\left({ }^{\circ} \mathrm{C}\right)$ & $-0,306$ & 0,047 & 40,927 & 0,73 & 0,000 \\
Temp. rad. média $\left({ }^{\circ} \mathrm{C}\right)$ & $-2,426$ & 0,037 & 41,066 & 0,78 & 0,000 \\
Velocidade do $\operatorname{ar}(\mathrm{m} / \mathrm{s})$ & 0,490 & 0,186 & 6,919 & 1,64 & 0,008 \\
Umidade do ar $(\%)$ & 0,011 & 0,007 & 2,107 & 0,00 & 0,146 \\
Radiação Solar $\left(\mathrm{W} / \mathrm{m}^{2}\right)$ & $-0,006$ & 0,001 & 0,126 & 0,00 & 0,260 \\
\hline
\end{tabular}

Tabela 8 - Efeito combinado entre variáveis ambientais e sensação térmica

\begin{tabular}{l|c|c|c|c|c}
\hline \multicolumn{5}{c}{ Sensação térmica - estimativa dos parâmetros / Regressão logística ordinal } \\
\hline Efeito Independente & Estimativa & Erro padrão & Test Wald & Razão da chance & Valor $\mathrm{p}$ \\
Temperatura do ar $\left({ }^{\circ} \mathrm{C}\right)$ & $-0,298$ & 0,048 & 38,521 & 0,74 & 0,000 \\
Velocidade do $\operatorname{ar}(\mathrm{m} / \mathrm{s})$ & 0,396 & 0,188 & 4,421 & 1,48 & 0,035 \\
Temp. Rad. Média $\left({ }^{\circ} \mathrm{C}\right)$ & $-0,235$ & 0,038 & 41,066 & 0,78 & 0,000 \\
Velocidade do $\operatorname{ar}(\mathrm{m} / \mathrm{s})$ & 0,387 & 0,189 & 4,198 & 1,74 & 0,000 \\
\hline
\end{tabular}

\section{Intervalo de conforto térmico}

O intervalo de conforto térmico foi estabelecido a partir dos votos de Sensação térmica (pergunta 1) que tem uma escala de 7 pontos (1 - Muito frio a 7 - Muito calor) em função de cada variável microclimática. É importante ressaltar que o intervalo encontrado está relacionado com a sensação térmica (pergunta 1) e não com o conforto térmico local (pergunta 6). A pergunta sobre sensação térmica foi melhor compreendida pelos entrevistados como "Conforto térmico" e possui uma escala mais ampla para sensação de conforto. Por isso, foi preferida para estabelecer o intervalo de conforto. Devido à sobreposição dos votos nas categorias 4 - neutro e 5 - pouco calor dentro do mesmo intervalo microclimático e também diante da informação que 773 (85\%) dos 900 entrevistados consideram-se termicamente confortáveis em relação ao microclima local, optou-se por considerar que pessoas com pouco desconforto para o calor possam estar em conforto térmico. Assim, foi assumido pelos autores na construção do gráfico que o intervalo de conforto corresponde às categorias 4 - neutro e 5-pouco calor. Já o desconforto para o calor corresponde às categorias 6 - calor e 7 - muito calor. Não foram encontrados votos nas categorias 1 - muito frio e 2 - frio, por isso não aparecem nos gráficos. A categoria 3 - pouco frio representa menos de $1 \%$ da amostra e foi, pelo mesmo motivo esclarecido acima, incluída no intervalo de conforto. Através das análises descritivas e de gráficos de dispersão tipo bolha foi possível verificar em quais condições microclimáticas está contida a maior parte dos votos da sensação de conforto (categorias 4 - neutro e 5 pouco calor). O eixo (x) representa as variáveis microclimáticas e o eixo (y) a sensação térmica. Nas Figuras 4 (a e b) e 5 (a e b) nota-se que existe sobreposição entre os votos de conforto (bolha azul) e desconforto para o calor (bolha laranja). Apesar da sobreposição dos votos de conforto, para 70\% da amostra, a sensação térmica de conforto (4 - Neutro e 5 - Pouco calor) esteve presente nas seguintes condições microclimáticas:

(a) temperatura do ar de 26 a $31{ }^{\circ} \mathrm{C}$; 
(b) temperatura radiante média de 24 a $34^{\circ} \mathrm{C}$;

(c) umidade do ar entre 50 e $80 \%$;

(d) radiação solar de 6 a $260 \mathrm{~W} / \mathrm{m}^{2}$; e

(e) velocidade do ar até $1,3 \mathrm{~m} / \mathrm{s}$.

Devido à baixa variação da velocidade do ar (média de $0,3 \mathrm{~m} / \mathrm{s}$ ) e a alta sobreposição dos votos não foi possível estabelecer um gráfico tipo bolha para esta variável, ficando estabelecido o valor máximo de $1,3 \mathrm{~m} / \mathrm{s}$ como intervalo de conforto. A Tabela 9 resume as informações contidas nas Figuras 4 e 5 . Dentro deste primeiro intervalo foi possível, ainda, identificar um segundo intervalo menor (destaque em vermelho nas Figuras 4 e 5) com algumas concentrações de votos:

(a) $26 \%$ destes votos estão concentrados entre a temperatura do ar de 27 a $28^{\circ} \mathrm{C}$;

(b) 55\% na temperatura radiante média de 28 a 32 ${ }^{\circ} \mathrm{C}$;

(c) 43\% entre a umidade do ar de 55 a 65\%; e

(d) radiação solar até $80 \mathrm{~W} / \mathrm{m}^{2}$.

A Tabela 10 resume as informações do intervalo menor.

\section{Figura 4 - Distribuição dos votos de sensação térmica e temperatura do ar (a) e Distribuição dos votos de sensação térmica e temperatura radiante média (b)}

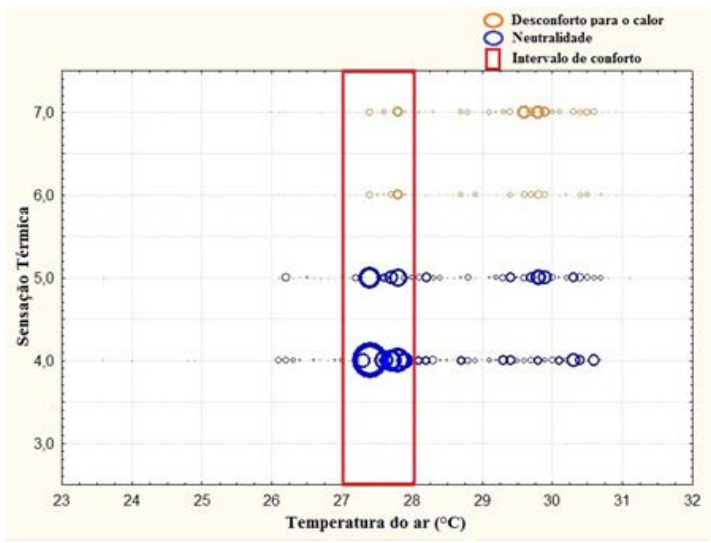

(a)

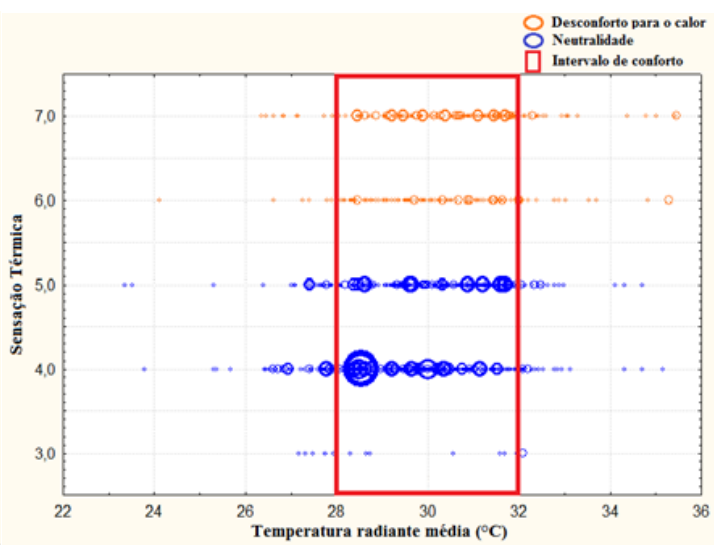

(b)

Figura 5 - Distribuição dos votos de sensação térmica e umidade ar (a) e Distribuição dos votos de sensação térmica e radiação solar (b)

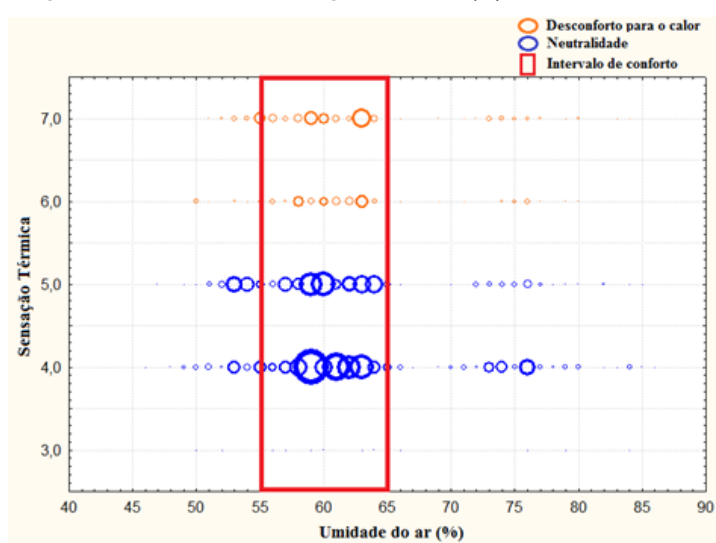

(a)

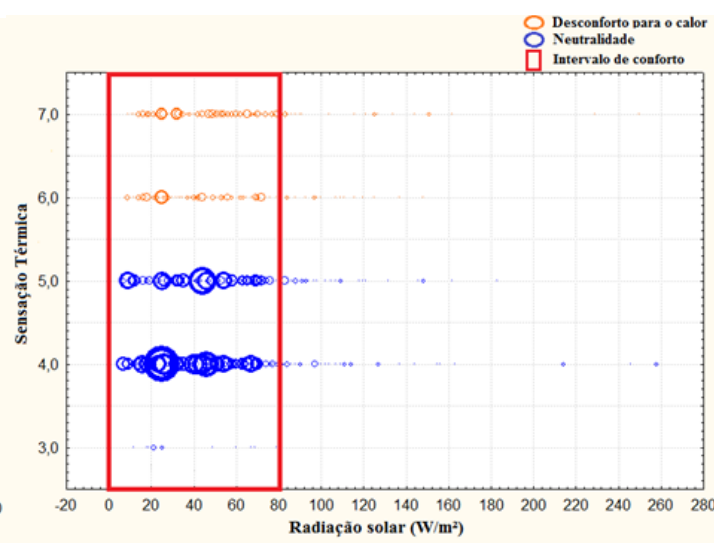

(b) 
Tabela 9 - Sensação térmica -Intervalo de Conforto para $\mathbf{7 0 \%}$ da amostra

\begin{tabular}{l|c|c|c}
\hline \multicolumn{4}{c}{ Sensação de conforto térmico } \\
\hline Variável microclimática & Média total & Intervalo de conforto & $\%$ Confortável \\
\hline Temperatura do ar & $28^{\circ} \mathrm{C}$ & $26^{\circ} \mathrm{C} \mathrm{a} 31^{\circ} \mathrm{C}$ & $70 \%$ \\
Temperatura radiante média & $29^{\circ} \mathrm{C}$ & $24^{\circ} \mathrm{C}$ a $34^{\circ} \mathrm{C}$ & $70 \%$ \\
Umidade do ar & $62 \%$ & $50 \%$ a $80 \%$ & $70 \%$ \\
Radiação solar & $50 \mathrm{~W} / \mathrm{m}^{2}$ & até $250 \mathrm{~W} / \mathrm{m}^{2}$ & $70 \%$ \\
Velocidade do ar & $0,3 \mathrm{~m} / \mathrm{s}$ & até $1,3 \mathrm{~m} / \mathrm{s}$ & $70 \%$ \\
\hline
\end{tabular}

Tabela 10 - Sensação térmica -Intervalo de Conforto

\begin{tabular}{l|c|c|c}
\hline \multicolumn{4}{c}{ Sensação de conforto térmico } \\
\hline Variável microclimática & Média total & Intervalo de conforto & $\%$ Connfortável \\
\hline Temperatura do ar & $28^{\circ} \mathrm{C}$ & $27^{\circ} \mathrm{C} \mathrm{a} 28^{\circ} \mathrm{C}$ & $26 \%$ \\
Temperatura radiante média & $29^{\circ} \mathrm{C}$ & $28^{\circ} \mathrm{C} \mathrm{a} 32^{\circ} \mathrm{C}$ & $55 \%$ \\
Umidade do ar & $62 \%$ & $55 \%$ a $65 \%$ & $43 \%$ \\
Radiação solar & $50 \mathrm{~W} / \mathrm{m}^{2}$ & até $80 \mathrm{~W} / \mathrm{m}^{2}$ & $62 \%$ \\
Velocidade do ar & $0,3 \mathrm{~m} / \mathrm{s}$ & até $1,3 \mathrm{~m} / \mathrm{s}$ & $70 \%$ \\
\hline
\end{tabular}

\section{Intervalo de conforto para PMV, PET e SET}

Seguindo a mesma sequência metodológica utilizada para encontrar o intervalo com bases nas variáveis ambientais, foram delimitados intervalos com base nos índices PMV, PET e SET, calculados com o auxílio do software Raymam 2.0. Nas Figuras 6 (a e b) e 7 pode-se observar a distribuição dos votos e o intervalo de conforto para os três índices calculados. Assim como no intervalo das variáveis ambientais existe sobreposição entre os votos de conforto (bolha azul) e desconforto para o calor (bolha laranja). Mesmo com a sobreposição dos votos de conforto, para $70 \%$ da amostra, a sensação de conforto (neutralidade) esteve presente nos seguintes intervalos calculados: PMV de -2,0 a +3,0; PET de $24{ }^{\circ} \mathrm{C}$ a $34{ }^{\circ} \mathrm{C}$ e SET de $14{ }^{\circ} \mathrm{C}$ a 31 ${ }^{\circ} \mathrm{C}$. A Tabela 11 resume as informações contidas nas Figuras 6 e 7. Dentro deste intervalo (70\% dos dados) também foi possível identificar um segundo intervalo menor (destaque em vermelho nas figuras 6 e 7) com algumas concentrações de votos:

(a) PMV de 59\%, entre +1 e +3,0; PET de 63\%, entre 26 e $32{ }^{\circ} \mathrm{C}$; e

(b) SET de $51 \%$, entre 17 e $24^{\circ} \mathrm{C}$ (Tabela 12).

Comparando o intervalo com temperatura do ar de 23 e $31^{\circ} \mathrm{C}$ e do PET de 24 e $34^{\circ} \mathrm{C}$ encontrado nesta pesquisa com outros intervalos de conforto em algumas cidades brasileiras de clima mais frio é possível observar uma tolerância maior ao calor. Para a cidade de Rio do Sul-SC, Sardo et al. (2013), utilizando o ITU ( índice de temperatura e umidade) encontraram intervalo de conforto de 12 a $22^{\circ} \mathrm{C}$; Para cidade de Campinas-SP, Pezzuto (2007) utilizou de regressão logística para estabelecer um intervalo de conforto com temperatura do ar de 17 a $27^{\circ} \mathrm{C}$; Labaki et al. (2012) delimitaram intervalos de PET de 21 a $30^{\circ} \mathrm{C}$ para Campinas-SP e de 14 a $24^{\circ} \mathrm{C}$ para Bauru e Presidente Prudente-SP. Embora o intervalo encontrado nessa pesquisa esteja distante dos intervalos para cidades com clima mais frio, quando comparados com cidades da região nordeste de clima mais quente, estes refletem maior tolerância das pessoas ao calor, tornando-as mais análogos. Costa e Araújo (2016) para Natal-RN delimitaram intervalo de conforto entre a temperatura do arde 24 a $30^{\circ} \mathrm{C}$ e umidade do ar entre 67e 89\%. Souza (2011) para Salvador-BA utilizou o índice PET definindo um intervalo de 26 a $29^{\circ} \mathrm{C}$. Moura, Zanella e Sales (2010) para Fortaleza-CE estabeleceram intervalo PET de24 a $34^{\circ} \mathrm{C}$. Estes diferentes intervalos mostram que as condições ambientais e de conforto térmico encontrado para cidades de clima quente e úmido, quente e seco, temperado e frio são diferentes, o que influencia diretamente na sensação térmica (BUENO, 1998). O intervalo do PMV de -2,0 a 3,0 mostra que este índice superestima a sensação de conforto real dos usuários, colocando maior parte dos votos em categorias de desconforto para o calor. Porém o intervalo para SET de 14 a $30^{\circ} \mathrm{C}$ concentra maior parte dos votos em categorias de desconforto para o frio, deste modo, estes dois índices não são indicados para estimar a sensação de conforto em espaços abertos em cidades de clima quente e úmido. Logo o índicePETfoi o que mais refletiu a sensação térmica real dos entrevistados. 
Figura 6 - Distribuição dos votos de sensação térmica e PMV (a) e Distribuição dos votos de sensação térmica e PET (b)

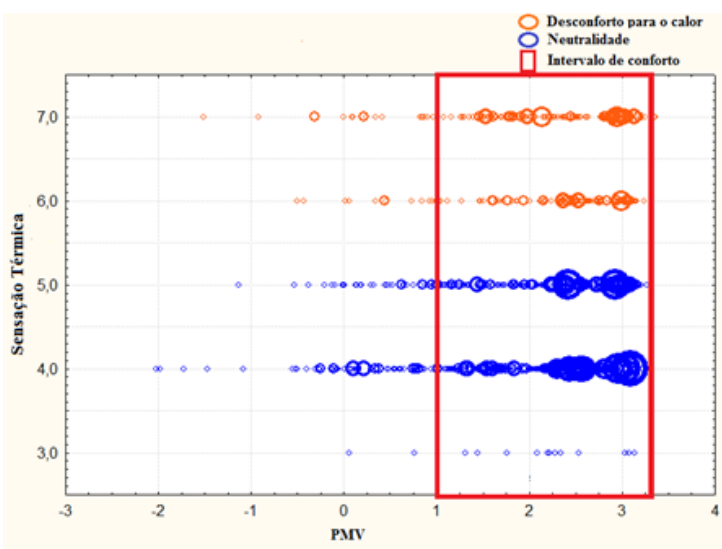

(a)

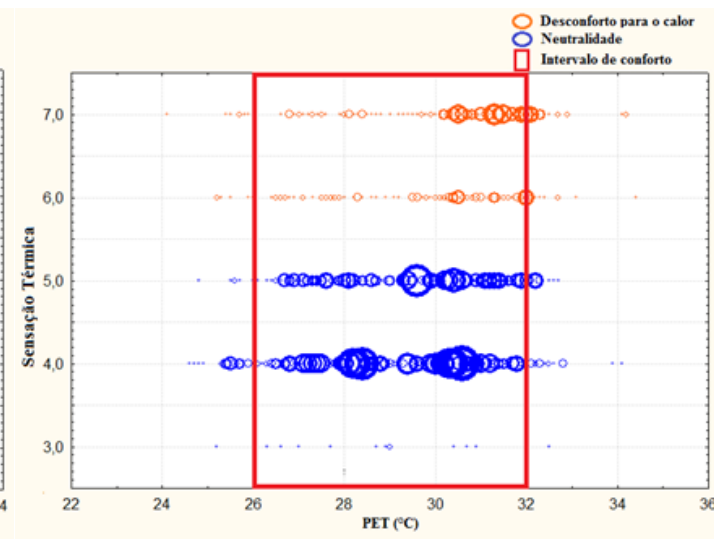

(b)

Figura 7 - Distribuição dos votos de sensação térmica e SET

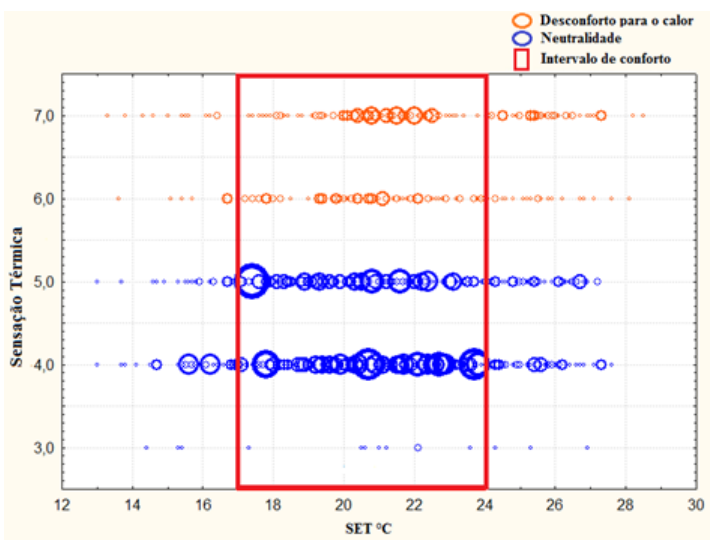

Tabela 11 - Índices calculados - Intervalo de conforto para $\mathbf{7 0 \%}$ da amostra

\begin{tabular}{l|c|c|c}
\hline \multicolumn{4}{c}{ Sensação de conforto térmico } \\
\hline Índice de conforto & Média total & Intervalo de conforto & $\%$ Confortável \\
\hline PMV & 2,5 & $-2,0 \leq$ PMV $\leq 3,0$ & $70 \%$ \\
PET & $29^{\circ} \mathrm{C}$ & $24^{\circ} \mathrm{C}$ a $34^{\circ} \mathrm{C}$ & $70 \%$ \\
SET & $21^{\circ} \mathrm{C}$ & $14^{\circ} \mathrm{C}$ a $30^{\circ} \mathrm{C}$ & $70 \%$ \\
\hline
\end{tabular}

Tabela 12 - Índices calculados - Intervalo para PMV, PET e SET

\begin{tabular}{l|c|c|c}
\hline \multicolumn{4}{c}{ Sensação de conforto térmico } \\
\hline Índice de conforto & Média total & Intervalo de conforto & \% Confortável \\
\hline PMV & 2,5 & $1,0 \leq$ PMV $\leq 3,0$ & $59 \%$ \\
PET & $29^{\circ} \mathrm{C}$ & $26^{\circ} \mathrm{C} \mathrm{a} 32^{\circ} \mathrm{C}$ & $63 \%$ \\
SET & $21^{\circ} \mathrm{C}$ & $17^{\circ} \mathrm{C}$ a $24^{\circ} \mathrm{C}$ & $51 \%$ \\
\hline
\end{tabular}

\section{Conclusão}

O Parque zoobotânico em estudo é percebido por 70\% dos usuários como um ambiente termicamente confortável. As variáveis microclimáticas estão intrinsecamente relacionadas com a sensação térmica das pessoas, sendo que, a temperatura do ar, temperatura radiante média e velocidade do ar foram as variáveis determinantes na sensação de conforto. A pouca ventilação foi percebida em ambos os períodos, sendo a opção "pouco ventilado” a mais sentida pelos usuários. Segundo Moura, Zanella e Sales (2010) a velocidade do vento é a variável de primeira ordem para o conforto 
térmico no meio urbano e é também a mais alterada pela urbanização. Apesar da ventilação no local ser insuficiente, ainda assim o ambiente em estudo foi considerado confortável por um grande número de entrevistados. Os limites de conforto, definidos a partir da amostra, apontam para uma maior tolerância a temperaturas mais elevadas, o que se deve em parte a aclimatação das pessoas com o clima local. As diferenças entre conforto real e os três índices de conforto calculados mostram que o PMV e SET não foram os índices mais indicados para estimar a sensação de conforto em espaços abertos em cidades de clima quente e úmido, sendo o PET o índice que melhor refletiu a sensação de conforto real dos entrevistados. Porém, os limites de PET proposto por Matzarakis, Rutz e Mayer (2006) e ajustado por Monteiro e Alucci (2007) para determinadas cidades brasileiras vão de 18 a $26^{\circ} \mathrm{C}$, sendo necessária assim uma calibração do índice para maior aproximação com as características climáticas reais da região estudada. Por fim, os resultados encontrados nesta pesquisa visam contribuir com os avanços dos estudos sobre conforto térmico em espaços abertos no clima tropical úmido.

\section{Referências}

BARBOSA, R. V. R. Áreas Verdes e Qualidade Ambiental Térmica em Ambientes Urbanos: estudo do microclima de Maceió (AL). São Carlos, 2005. Dissertação (Mestrado em Ciências da Engenharia Ambiental) - Escola de Engenharia de São Carlos - Universidade de São Paulo, 2005.

BUENO, C. L. Estudo da Atenuação da Radiação Solar Incidente Por Diferentes Espécies Arbóreas Campinas-SP. Campinas, 1998. 177 f. Dissertação (Mestrado em Engenharia Civil) - Faculdade de Engenharia Civil, Universidade Estadual de Campinas, Campinas, 1998.

COSTA, A.; ARAÚJO, V. Contribuição Para a Definição De faixas-Limite de Conforto Térmico Para Ambientes Externos. In: ENCONTRO NACIONAL DE TECNOLOGIA DO

AMBIENTE CONSTRUÍDO, Florianópolis, 2016. Anais... Florianópolis: ANTAC, 2016.

DACANAL, C.; LABAKI C. L; SILVA, T. M. L; Vamos Passear na Floresta! O conforto térmico em fragmentos florestais urbanos. Ambiente

Construído, Porto Alegre, v. 10, n. 2, p. 115-132, abr./jun. 2010.

FANGER, P. O. Thermal Comfort: analysis and applications in environmental engineering. United State: McGraw-Hill Book Company, 1970.
GAGGE, A. et al. A Standard Predictive Index of Human Response to the Thermal Environment. ASHRAE Trans, v. 92, p. 709-731, 1986.

HIRASHIMA S. Q. S. Calibração do Índice de Conforto Térmico Temperatura Fisiológica Equivalente (PET) Para Espaços Abertos do Município de Belo Horizonte-MG. Belo Horizonte, 2010. Dissertação (Mestrado em Ambiente construído e Patrimônio Sustentável) Escola de Arquitetura, Universidade Federal de Minas Gerais, Belo Horizonte, 2010.

HIRASHIMA, S. Q. S. Percepção Sonora e Térmica e Avaliação de Conforto em Espaços Abertos do Município de Belo Horizonte - MG. São Paulo, 2014. Tese (Doutorado em Tecnologia da Arquitetura) - Faculdade de Arquitetura e Urbanismo, Universidade de São Paulo, 2014.

HÖPPE, P. The physiological Equivalent Temperature: a universal index for the biometeorological assessment of the thermal environment. International Journal of Biometeorology, v. 43, p. 71-75, 1999.

HUMPHREYS, M. A. Outdoor Temperatures and Comfort Indoors. Building Research and Practice, v. 6, n. 2, 1978.

INTERNATIONAL ORGANIZATION FOR STANDARDIZATION. ISO 7726: ambientes térmicos: instrumentos e métodos para medições das quantidades físicas. Genebra, 1998.

\section{INTERNATIONAL ORGANIZATION FOR} STANDARDIZATION. ISO 7730: ergonomics of the thermal environment: analytical determination and interpretation of thermal comfort using calculation of the PMV and PPD indices and local thermal comfort criteria. Geneva, 2005.

JOÃO PESSOA. Plano Nacional de Conservação da Mata Atlântica da Cidade de João Pessoa. 2012. Disponível em:

$<$ https://issuu.com/pmjponline/docs/seman_mata_a tlantica/65?e=3962434/2805617>. Acesso em: 05 out. 2016.

LABAKI, L. C. et al. Conforto Térmico em Espaços Público de Passagem: estudo em ruas de pedestres no estado de São Paulo, Ambiente Construído, Porto Alegre, v. 12, n. 1, p. 167-183, jan./mar. 2012.

MAHMOUD, A. H. A. Analysis of the Microclimatic and Human Comfort Conditions in an Urban Park in Hot and Arid Regions. Building and Environment, v. 46, n. 12, p. 2641-2656, 2011. 
MATZARAKIS, A.; RUTZ, F.; MAYER, H. Modelling the Thermal Bioclimate in Urban Áreas With the RayMan Model. In: INTERNATIONAL CONFERENCE ON PASSIVE AND LOW ENERGY ARCHITECTURE, 23., Genève, 2006. Proceedings... Genève: Université de Genève, 2006.

MATZARAKIS, A.; RUTZ, F. Application of the RAYMAN Model in Urban Environments. Freiburg: Meteorological Institute, University of Freiburg, 2010.

MONTEIRO, C. A. F. Adentrar a Cidade Para Tomar-lhe a Temperatura. GEOSUL, v. 9, 1990.

MONTEIRO, L. M.; ALUCCI, M. P. Questões Teóricas de Conforto Térmico em Espaços Abertos: consideração histórica, discussão do estado da arte e proposição de classificação de modelos. Ambiente Construído, Porto Alegre, v. 7, n. 3, p. 43-58, jul./set. 2007.

MOURA, M. O.; ZANELLA, M. E.; SALES, M. C. L. Conforto Térmico em Fortaleza-CE. ANPEGE. v. 6, p. 177-189, 2010.

NG, E.; CHENG, V. Urban Human Thermal Comfort in hot and humid Hong Kong. Energy and Buildings, v. 55, p. 51-65, 2012.

NIKOLOPOULOU, M.; LYKOUDIS, S. Thermal Comfort in Outdoor Urban Spaces: analysis across different European countries. Building and

Environment, Oxford, v. 41, n. 11, p. 1455-1470, 2006.

NIKOLOPOULOU, M.; STEEMERS, K. Thermal Comfort and Psychological Adaptation as a Guide for Designing Urban Spaces. Energy and

Buildings, Lausanne, v. 35, p. 95-101, 2003.

NIKOLOPOULOU, M.; LYKOUDIS, S. Thermal Comfort in Outdoor Urban Spaces: analysis across different European countries. Building and Environment, Oxford, v. 41, n. 11, p. 1455-1470, nov. 2006.

NÓBREGA, R. S.; LEMOS, T. V. S. O

Microclima e o (des) Conforto Térmico em Ambientes Abertos na Cidade do Recife. Revista de Geografia, v. 28, n. 1, 2011.
PROJETO Ruros. Disponível em: $<$ http://alpha.cres.gr/ruros>. Acesso em: 05 out. 2016.

PEZZUTO, C. C. Avaliação do Ambiente Térmico nos Espaços Urbanos Abertos: estudo de caso Campinas. Campinas, 2007. Tese (Doutorado em Engenharia Civil) - Faculdade de Engenharia Civil, Universidade Estadual de Campinas, Campinas, 2007..

ROSSI, F. A.; KRUGER, E. D.; BRODE, P. Definição de Faixa de Conforto e Desconforto Térmico Para Espaços Abertos em Curitiba-PR, Com Índice de UTCI. Ambiente Construído, Porto Alegre, v. 12, n. 1, p. 41-59, jan./mar. 2012. RUIZ, M. A.; CORREA, E. N. Adaptative Model For Outdoor Thermal Comfort Assessment in as Oasis City of Arid Climate. Building and Environment, v. 85. p. 40- 51, 2015.

SARDO, J. et al. Análise do Índice de Sensação Térmica Para a Cidade de RIO DO SUL/SC. Enciclopédia Biosfera, Centro Científico Conhecer,- Goiânia, v. 9, n. 17; p. 154, 2013.

STATSOFT, Inc. Statistica (data analysis software system), version 7.0. 2004.

SOUZA, S. H. M. Avaliação do Desempenho Térmico nos Microclimas das Praças: Piedade e Visconde de Cayrú, Salvador, 2011. In: ENCONTRO NACIONAL DE CONFORTO NO AMBIENTE CONSTRUÍDO, Salvador, 2011. Anais... Salvador, 2011

TSITOURA, M.; TSOUTSOS, T.; DARAS, T. Evaluation of Comfort Conditions in Urban Open Spaces: application in the island Crete. Energy Conversion and Management, v. 86, p. 250-258, 2014.

\section{Agradecimentos}

Os autores agradecem à CAPES pela bolsa de mestrado que possibilitou o desenvolvimento dessa pesquisa. 


\section{Linccon de Carvalho Lima}

Programa de Pós-Grauduação em Engenharia Civil e Ambiental | Universidade Federal da Paraíba | Cidade Universitária, s/n, Centro de Tecnologia, Campus I, Castelo Branco III | J oão Pessoa - PB - Brasil | CEP 58051-085 | E-mail: linccon.ecobio@hotmail.com

\section{Solange Maria Leder}

Departamento de Arquitetura, Centro de Tecnologia | Universidade Federal da Paraíba | Campus I, Cidade Universitária, Castelo Branco | J oão Pessoa - PB - Brasil | CEP 58059-900 | Tel.: (83) 3216-7378 | E-mail: solangeleder@yahoo.com.br

\section{Luiz Bueno da Silva}

Departamento de Engenharia de Produção, Centro de Tecnologia | Universidade Federal da Paraíba | Bloco G, Cidade Universitária, Castelo Branco III | J oão Pessoa - PB - Brasil | Caixa Postal 5045 | CEP 58051-970 | Tel.: (83) 3216-7685 | E-mail: elopesouza@gmail.com

\section{Erivaldo Lopes de Souza}

Departamento de Engenharia de Produção, Centro de Tecnologia | Universidade Federal da Paraíba | E-mail: elopesouza@gmail.com

\section{Revista Ambiente Construído}

Associação Nacional de Tecnologia do Ambiente Construído

Av. Osvaldo Aranha, 99 - 3o andar, Centro

Porto Alegre - RS - Brasil

CEP 90035-190

Telefone: +55 (51) 3308-4084

Fax: +55 (51) 3308-4054

www. seer. ufrgs. br/ ambienteconstruido

E-mail: ambienteconstruido@ufrgs.br 